\title{
POR UMA OUTRA ESCOLA: PROVOCAÇÕES À DIDÁTICA E AO CONCEITO DE INOVAÇÃO PEDAGÓGICA
}

\author{
POR UNA OTRA ESCUELA: PROVOCACIONES A LA DIDACTICA Y EL \\ CONCEPTO DE INNOVACIÓN PEDAGÓGICA
}

\author{
FOR ANOTHER SCHOOL: PROVOCATIONS TO DIDACTIS AND \\ PEDAGOGICAL INNOVATION CONCEPT
}

\author{
Mônica VASCONCELLOS ${ }^{1}$ \\ Sandra MACIEL ${ }^{2}$
}

\begin{abstract}
RESUMO: Identificar elementos que apontem perspectivas pedagógicas inovadoras, sob a ótica de licenciandos e de professores da educação básica é o objetivo deste estudo que resulta das reflexões realizadas pela equipe docente do Núcleo de Didática e Formação de Professores da UFF e das avaliações qualitativas realizadas com alunos de Didática. Isso nos provocou a propor uma (re)aproximação com a escola, o que gerou registros individuais e entrevistas com docentes da escola básica, considerados inovadores pelos licenciandos. Na contramão da vinculação do conceito de inovação pedagógica à inserção de aparatos tecnológicos, os licenciandos expressaram preocupações com a construção de uma sociedade mais justa, calcada em aspectos como autonomia docente, dialogicidade, compromisso e criatividade. $\mathrm{O}$ reconhecimento político e social de que a escola é o principal locus de formação humana e a urgência de refletirmos coletivamente sobre outras formas de se pensar e se fazer escola são perspectivas de nossas discussões.
\end{abstract}

PALAVRAS-CHAVE: Didática. Inovação pedagógica. Licenciatura.

RESUMEN: Identificar los elementos que señalan la perspectiva pedagógica innovadora, desde la perspectiva de licenciandos y maestros de educación básica es el objetivo de este estudio es el resultado de las reflexiones realizadas por la equipo docente del Núcleo de Didáctica y Formación de Profesores de la UFF y de las evaluaciones cualitativas realizadas con estudiantes de didáctica. Esto nos hizo proponer un (re)aproximación más cercano a la escuela, los registros individuales y entrevistas con los profesores de la escuela primaria, considerados innovadores por los licenciandos. Contra de vincular el concepto de innovación pedagógica la inserción de aparatos tecnológicos, los licenciandos expresaron su preocupación con la construcción de una sociedad más justa, basada en aspectos como el compromiso de autonomía, diálogo y creatividad. El reconocimiento político y social de la escuela es el

\footnotetext{
${ }^{1}$ Universidade Federal Fluminense (UFF), Niterói - RJ - Brasil. Docente no Departamento Sociedade, Educação e Conhecimento (SSE). ORCID: https://orcid.org/0000-0003-2938-2121. E-mail: monicavasconcellos@id.uff.br

${ }^{2}$ Universidade Federal Fluminense (UFF), Niterói - RJ - Brasil. Docente no Departamento Sociedade, Educação e Conhecimento (SSE). ORCID: https://orcid.org/0000-0001-5201-0735. E-mail: sandramacieldealmeida@gmail.com
} 
lugar principal de la formación humana y la necesidad urgente de reflexionar colectivamente sobre otras maneras de pensar y hacer escuela son perspectivas para nuestros debates.

PALABRAS CLAVE: Didáctica. Innovación pedagógica. Grado.

ABSTRACT: Identifying elements pointing basic education and innovative pedagogical perspectives from undergraduates and teachers perspective is the aim of this study, resulting in teaching staff reflections by UFF Center for Teaching and Training of Teachers and qualitative evaluations carried out with students of Didactic Discipline. It promoted a (re)approximation with the school, generating individual records and interviews with basic school teachers, considered innovative by the graduates. In contrast to linking the concept of pedagogical innovation to technological apparatuses insertion, the fellow students expressed preoccupations with a more fair society construction, based on aspects such as teaching autonomy, dialogue, commitment and creativity. The political and social school recognition is the main locus of human formation and community, reflecting urgency on other scholar thinking and conducting ways are perspectives of the present discussion.

KEYWORDS: Didactics. Pedagogical innovation. Graduation.

\section{Entremeando teorias e metodologias introduzimos a discussão}

Os espaços formativos são cenários propícios à potencialização de atitudes transgressoras (HERNÁNDEZ, 1998) tendo em vista o volume e o teor das relações que neles se instituem, atravessadas por pressões políticas e sociais nem sempre condizentes com as demandas dos/as estudantes e das professoras e professores.

$\mathrm{Na}$ universidade isso não é diferente e a adoção de práticas transgressoras é elemento essencial da dinâmica acadêmica, cuja produção de conhecimento exige postura investigativa na busca por metodologias pouco usuais e respostas para perguntas, muitas vezes, ainda sem solução. No caso das universidades públicas, além dos aspectos mencionados, alunos, professores, gestores e servidores têm convivido com pressões decorrentes da propagação de ideias distorcidas que buscam deslegitimar sua própria história e negar suas contribuições. Imersa em ambientes que sofrem as consequências da forte diminuição orçamentária, a comunidade acadêmica permanece trabalhando em precárias condições de infraestrutura nas quais professores se desdobram no cumprimento da intensa carga de trabalho em concomitância ao atendimento das exigências institucionais das mais diversas instâncias. 
No caso específico dos cursos de licenciatura, esses fatores são acrescidos das sérias consequências acarretadas por políticas públicas fragmentadas, descontínuas, inconstantes e, muitas vezes, incoerentes que alimentam o desprestígio social do próprio magistério ocasionando evasão de estudantes matriculados nos cursos de licenciatura, desinteresse pela sua conclusão e abandono da profissão.

O Censo da Educação Superior (BRASIL, 2016) destaca que em 2014, o nível de evasão no curso de Pedagogia, por exemplo, chegou a $39 \%$, enquanto cursos como Física, Química e Matemática têm taxas de 57,2\%,52,3\% e 52,6\% respectivamente.

Se, de um lado, um quadro complexo como este pode gerar estagnação, de outro, é propício à criação de percursos formativos que produzam rupturas e gerem transgressões em razão dos desafios suscitados frente à natureza político-epistemológica dos próprios cursos que, em linhas gerais, têm a responsabilidade de formar os professores da educação básica do nosso país.

Movidas por este entendimento e inspiradas por estudos do campo (CANDAU, 2012; GATTI, 2013; GAUTHIER, 1998; NÓVOA, 2015, entre outros), em 2017, professoras $^{3}$ de Didática da Faculdade de Educação da Universidade Federal Fluminense (FEUFF) publicaram um texto intitulado Ensino de Didática: entre ressignificações e possibilidades na FEUFF (DOMINICK, VASCONCELLOS e ALVES et al., 2017). O texto é parte do livro denominado Ensino de Didática: entre ressignificações e possibilidades, organizado por professoras da Faculdade de Educação da Universidade Federal do Rio de Janeiro (CRUZ, OLIVEIRA e NASCIMENTO, 2017). Nele,

[...] apresentamos o movimento que o grupo de professores de Didática da Faculdade de Educação da Universidade Federal Fluminense (FEUFF/UFF), campus Gragoatá/Niterói-RJ, vem realizando desde 2015, buscando a reorganização da área a partir da definição e compreensão de sua especificidade teórico-prática no contexto da nossa faculdade. [...] Trata-se de um movimento de identificação e delineamento das possibilidades e limites da Didática para situá-la na instituição e mostrar a sua importância na formação de professores (DOMINICK; VASCONCELLOS; ALVES et al., 2017, p. 49).

Rechaçando a ideia da Didática como campo de teorizações descomprometidas com a escola, com as práticas e com a profissão docente e, em oposição ao entendimento de que sob sua ótica estão assentadas técnicas de ensino encerradas em si

\footnotetext{
${ }^{3}$ Considerando que o grupo é formado por 9 professoras e 1 professor, optamos por utilizar o feminino.
} 
mesmas, no mesmo período, o conjunto de professoras de Didática da FEUFF constituiu o Núcleo de Didática e Formação de Professores/CNPq ${ }^{4}$. Atualmente, o Núcleo é composto por 10 professoras que trabalham nesta área e, semestralmente, ministram aulas para cerca de 400 alunos matriculados em mais de 20 cursos de licenciatura da UFF.

Desde 2017, os membros se reúnem mensalmente para discutir, definir e avaliar questões da área, compartilhar os modos como pensam, organizam e implementam suas aulas; trocar informações acerca dos referenciais teóricos com os quais trabalham, dialogar sobre os procedimentos metodológicos que empregam e as formas de avaliação que implementam. Nestas ocasiões, se dispõem a ouvir críticas e sugestões em torno do trabalho que desenvolvem, conversar com os pares sobre o que pensam, como agem e como justificam suas escolhas diante da abordagem de conteúdos expressos na ementa que corresponde à disciplina, cujos encaminhamentos e bibliografia são bastante distintos.

Esta dinâmica tem se mostrado rica em virtude da garantia do espaço de escuta coletiva e do respeito mútuo pelas diferenças, o que tem favorecido a oportunidade de conhecer em maior profundidade o tipo de trabalho que cada professora implementa, bem como suscitado a revisão das próprias práticas e inspirado a constituição de perspectivas teórico-metodológicas variadas.

Foi em uma das reuniões organizadas pelo Núcleo que tivemos a oportunidade de trocar informações com os demais integrantes acerca do trabalho que temos realizado nas turmas dos cursos de licenciatura da UFF, cujo enfoque está pautado pela compreensão da ideia de que a formação de professores requer o reconhecimento e a valorização dos saberes docentes e dos conhecimentos profissionais (TARDIF, 2014; SCHULMAN, 1987) como fundamentos deste processo. Na ocasião tivemos a oportunidade de destacar que não menos importante é a adoção contínua de encaminhamentos alinhados com princípios democráticos que contemplem a horizontalidade e a afetividade nas relações; o entendimento da escola e da universidade como espaços legítimos de produção de conhecimentos, de formação docente e de potencialização da emancipação humana.

Em nossa ótica, chamar atenção para esta abordagem é essencial por evidenciar sua contraposição aos modelos de formação mais conservadores, nos quais a “[...] aula

\footnotetext{
${ }^{4}$ As autoras do presente artigo, além de serem professoras de Didática da Faculdade de Educação da UFF, integram o Núcleo de Didática e Formação de Professores - UFF/CNPq.
} 
se constitui num espaço de ordem, desde a organização das classes e dos estudantes até o reconhecimento de que algumas disciplinas são mais importantes que outras". (CUNHA, 2016, p. 90).

As avaliações qualitativas que temos realizado com os alunos durante e ao final da disciplina nos levam a perceber que a adoção desta perspectiva, em certa medida, transgride em sentidos variados quando comparada aos processos formativos aos quais boa parte dos licenciados e seus formadores estiveram vinculados no decorrer do período de escolarização. Consideramos que ao imergir neste trabalho e serem incitados a refletir e a agir com/sobre ele é possível que os futuros professores passem a constituir aprendizagens profissionais afinadas com os princípios elencados e desse modo sejam inspirados a refletir coletivamente sobre outras formas de se pensar e se fazer escola.

Ao mesmo tempo em que nos move, esta suposição provoca outros questionamentos: até que ponto este trabalho tem contribuído com a revisão das concepções dos licenciandos em torno da ideia de escola e de formação de professores? Em que medida, o teor abordado e o encaminhamento adotado têm favorecido a constituição de conhecimentos profissionais que transgridem com enfoques conservadores? Transgredir com esses enfoques significa estabelecer uma aproximação com a ideia de inovação pedagógica?

Para as perguntas formuladas ainda não temos respostas contundentes, no entanto, julgamos importante tecer alguns comentários acerca do conceito de inovação pedagógica. Isso porque, embora não seja extensa a produção sobre o tema, o pouco que se difundiu até o momento não expressa com clareza o entendimento dos autores sobre o assunto, dando a entender que se trata de um conceito autoexplicativo. Inclusive, é comum encontrar publicações que aliam inovação pedagógica às tecnologias digitais em processos de ensino e aprendizagem ocorridos no ambiente escolar e/ou acadêmico.

Em oposição a este entendimento, o conceito de inovação pedagógica com o qual nos afinamos ultrapassa a ideia de que o uso de aparatos tecnológicos em si representa inovação, pois compreendemos que os sujeitos inovam, sobretudo em relação às suas atitudes, e não aos objetos (VASCONCELLOS; SANTIAGO, 2018). Dito de outro modo, a inovação pedagógica requer

[...] ruptura paradigmática que exige dos professores reconfiguração de saberes e reconhecimento da necessidade de trabalhar no sentido de transformar [...] a 'inquietude' em energia emancipatória', ou seja, trata-se de "[...] uma nova forma de compreender o conhecimento [...] 
[provocando] uma alteração nas bases epistemológicas da prática pedagógica (CUNHA, 2016, p. 8).

A estes esclarecimentos acrescentamos o reconhecimento da diferença como valor e a qualidade das relações sociais que se constroem com os alunos como preponderante.

Instigadas por esta perspectiva organizamos a disciplina e propusemos aos alunos de Didática da FEUFF, que se debruçassem sobre os estudos sugeridos e realizassem atividades que pudessem provocá-los a pensar uma escola transgressora ou inovadora, como definido por Cunha (2016).

Neste artigo discutimos e problematizamos duas dessas atividades, articuladas entre si, propostas pelas duas professoras de Didática, autoras desse artigo. São elas: 1) (re)aproximação com a escola básica, seguida de debate coletivo e registro individual; 2) Entrevista com docentes da escola básica, considerados inovadores pelos licenciandos e análise dos depoimentos com base na literatura.

Cabe esclarecer que a (re)aproximação com a escola foi tratada pelas duas docentes e por suas 3 respectivas turmas, como atividade de campo. Uma das professoras, não atribuiu notas à realização ou à elaboração dos registros produzidos pelos licenciandos. Mesmo assim, a participação das suas duas turmas foi completa (55 alunos) gerando, inclusive, a solicitação de mais de uma carta de apresentação por licenciando, em razão da intenção de alguns de se integrarem a mais de uma escola. 28 desses sujeitos, elaboraram e entregaram os referidos registros que, após cuidadosa leitura, suscitaram a seleção de 5 deles ocasionados pela identificação de aspectos representativos dos demais. Feito isso, organizamos, descrevemos e analisamos as informações adquiridas em sintonia com o objetivo delineado e em consonância com as contribuições dos estudiosos que compõem nosso quadro teórico.

$\mathrm{O}$ outro repertório de dados analisados tem origem em 13 entrevistas que os licenciandos da terceira turma implementaram com professores/as das escolas básicas nas quais a atividade ocorreu. As entrevistas foram filmadas e editadas pelos alunos dos cursos de licenciatura partícipes, posteriormente apresentadas durante as aulas, seguidas de debate sobre o conceito de inovação pedagógica, provocado pelos depoimentos dos entrevistados. Dentre os 13 vídeos produzidos e exibidos em aula, selecionamos trechos dos esclarecimentos de 5 professores da Educação Infantil, do Ensino Fundamental e do Ensino Médio, escolhidos aleatoriamente: Maria, Andreia, Richard, Augusto e Adriane. 
Para que pudéssemos analisar seus depoimentos, tornamos a assistir os vídeos e nos dedicamos a transcrever as informações compartilhadas. Destaca-se que os alunos escolheram professores e professoras que eles consideravam que tem uma prática inovadora, mas na entrevista que realizaram eles não perguntaram aos docentes o que seria inovação, mas sim, pediram para falar sobre suas práticas pedagógicas, as metodologias utilizadas, o significado da docência para cada um. A proposta foi que fizessem entrevistas abertas e que, ao entrevistar tivessem escuta para o que os professores tinham a dizer, sem induzir respostas, mas, que, de fato, demostrassem interesse e curiosidade para o que os professores tinham a dizer sobre seus trabalhos.

Ao revisitar as entrevistas, um semestre depois (maio de 2019), foram feitas transcrições de todo material, que foi analisado e categorizado. Dentre as categorias que tiveram destaca na análise, destaca-se Inovação Pedagógica como o macro-tema e os subtemas: escuta, dialogicidade, criatividade e autonomia docente.

É com base nestes dois materiais - vídeos com as entrevistas dos professores da educação básica e registros por escrito dos licenciandos - que nossa investigação foi realizada, tomando por base os estudos sobre o desenvolvimento de pesquisas qualitativas (LÜDKE; ANDRÉ, 2004; MINAYO, 2003). Dito isso, esclarecemos que nosso intuito é identificar elementos que apontem perspectivas pedagógicas inovadoras, sob a ótica de licenciandos e de professores da educação básica.

Dito isso, informamos que no próximo item, faremos uma breve sistematização sobre as discussões da área da Educação em torno do debate sobre a formação docente, seguida das análises dos dados coletados nas duas atividades propostas, quando abordaremos a questão da inovação pedagógica em diálogo com o material selecionado para esta investigação.

\section{Formar para a inovação ou formar inovando?}

Na realização do seu trabalho, os professores empregam frequentemente

[...] seus conhecimentos pessoais e um saber-fazer personalizado, trabalham com os programas e livros didáticos, baseiam-se em saberes escolares relativos às matérias ensinadas, fiam-se em sua experiência e retêm certos elementos de sua formação profissional (TARDIF, 2014, p. 64). 
Acontece, porém, que eles nem sempre têm consciência da natureza dos saberes que empregam ou dos motivos que os levaram a adotá-los. Agem como se suas ações caminhassem de maneira espontânea/autônoma, de forma "natural", sem a necessidade de elaborar explicações para justificá-las. Essa

[...] inconsciência não é necessariamente produto de uma recusa, de mecanismos de defesa, como os descreve a psicanálise. Em geral, é um 'inconsciente prático', segundo a fórmula de Piaget, produto de um esquecimento progressivo a mercê da formação de rotinas, ou de um desconhecimento de sempre, um simples efeito da impossibilidade e da inutilidade de estarmos permanentemente conscientes de nossos atos e de nossas motivações (PERRENOUD, 2001, p. 161).

Embora muitas vezes inconscientes, os saberes mobilizados pelos professores foram modelados durante sua história de vida e de socialização (pré-profissional e profissional) e como estão enraizados acreditam que fazem parte de sua personalidade e por esse motivo são considerados "inatos" ou "naturais".

Essa naturalização e essa personalização do saber profissional são tão fortes que resultam em práticas as quais, muitas vezes, reproduzem os papéis e as rotinas institucionalizadas da escola (TARDIF, 2014, p. 78).

Isto porque, os saberes ligados à experiência começam a ser constituídos a partir do ingresso no magistério e é justamente nesse "[...] início da carreira que [sua] estruturação [...] é mais forte e importante" (IBID., p. 86), pois em função de sua experiência, pouco a pouco passam a ter certezas acerca daquilo que desenvolvem no meio escolar e assim começam a se sentir integrados e capacitados para exercer seu trabalho. Comumente, ao se defrontarem com as adversidades, julgam a formação inicial e indicam que há "[...] uma defasagem, uma distância crítica” entre os saberes adquiridos na formação e os problemas que precisam enfrentar. Nesse processo, novos entendimentos relacionados ao exercício da docência são tecidos (TARDIF, 2014; NÓVOA, 2015) e, na maior parte das vezes isso ocorre porque

[...] os saberes ligados ao trabalho são temporais, pois são construídos e dominados progressivamente durante um período de aprendizagem variável, de acordo com cada ocupação", portanto, é na implementação do trabalho que tais adversidades emergem e fazem com que os professores mobilizem conhecimentos específicos na tentativa de superá-las, exigindo que [...] desenvolvam, progressivamente, saberes gerados e baseados no próprio processo de trabalho (TARDIF, 2014, p. 58). 
Para que dificuldades dessa natureza sejam minimizadas, estudiosos do assunto têm apontado a necessidade de envolver os futuros professores em estudos e situações que os levem a compreender

[...] a centralidade do conhecimento do objeto no que diz respeito ao ensino e às consequências da falta desse conhecimento. [...] precisam aprender sobre os conceitos centrais e a organização de princípios de um conteúdo (SHULMAN; GROSSMAN; WILSON, 1989, p. 28).

Os resultados de algumas das pesquisas (GAUTHIER, 1998; TARDIF, 2014; TERRIEN, 1993) realizadas a propósito da mobilização dos saberes adquiridos na história de vida (principalmente da vida escolar) dos professores, coadunam com as informações reveladas pelas investigações que desenvolvemos a respeito de prováveis relações entre as experiências escolares e a atuação profissional de professoras iniciantes (MACIEL; JAEHN; VASCONCELLOS, 2018; VASCONCELLOS; OLIVEIRA; MENEZES, 2016).

Em uma dessas investigações destaca-se nos depoimentos que emergiram o entendimento de que ao ingressar na carreira, os participantes afirmaram que se depararam com uma realidade bastante distinta daquela que idealizaram durante o período de formação inicial. Frente aos problemas que surgiam e diante da urgência que o contexto escolar requeria, tomavam decisões que nem sempre se "afinavam" com seus pontos de vista, seja porque contrariavam os estudos realizados durante a graduação ou porque não tinham clareza sobre as razões que os levaram a agir daquele modo. Isso gerava angústia e fazia com que se sentissem “[...] bem ou mal com esta ou com aquela maneira de trabalhar na sala de aula" (NÓVOA, 1999, p. 16).

Para melhor compreender esta relação, advertimos que frequentemente os professores empregam práticas inspiradas em situações que derivam de suas experiências acadêmicas, escolares ou das suas histórias de vida (TARDIF, 2014). Ao empregá-las, as "reatualizam" e "reutilizam" como forma de enfrentar as situações advindas dos contextos nos quais estão imersos, sem que para isso seja necessário ter consciência dessa retomada. Esta retomada, por sua vez, tem relação com o fato de que antes mesmo de começar a atuar os docentes convivem, como alunos, com seu ambiente de trabalho por um longo período de tempo, proporcionando a construção de 
compor um conjunto de saberes pré-profissionais [...] que serão mobilizados e utilizados [...] no exercício do magistério (TARDIF, 2014, p. 68-69).

Assim, ao retornarem às escolas, “[...] por ocasião dos estágios [...], os professores em formação tendem a prestar mais atenção nos fenômenos da sala de aula em relação aos quais eles possuem expectativas ou representações fortes" (IBID., p. 70) que foram tecidas durante essa trajetória. Por esse motivo, acreditamos que a atenção dos formadores deve estar voltada para esse aspecto e, nesse sentido, precisam implementar práticas que também enfoquem aquilo que foi ignorado, na tentativa de favorecer a superação das crenças que carregam consigo e a ampliação do seu repertório de saberes.

Temos consciência de que ainda é longo o caminho que precisamos percorrer na busca pela melhoria e pela valorização da formação e do trabalho docente e acreditamos que uma das possibilidades envolve a assunção da ideia de que um dos

[...] importantes papéis da formação inicial seria o de alterar quadros de referência prévios dos futuros professores sobre a atividade escolar, os alunos, o contexto escolar, os conteúdos escolares etc (MIZUKAMI, 2006, p. 152).

Isso pode ocorrer mediante

[...] análise das práticas, das tarefas e dos conhecimentos dos professores de profissão; [...] por meio de um enfoque reflexivo, levando em conta os condicionantes reais do trabalho docente e as estratégias utilizadas para eliminar esses condicionantes na ação (TARDIF, 2014, p. 242).

Reflexões como estas têm influenciado nossas ações como pesquisadoras e como formadoras de professores, nos levando a avaliar nossas práticas, seja de modo individual; nas reuniões do Núcleo de Didática e Formação de Professores ou com os alunos das turmas envolvidas. Este processo de reflexão nos levou a perceber a necessidade de integrar os licenciandos ao espaço escolar de forma mais efetiva e por uma via que não fosse somente pelo estágio obrigatório.

Para tanto, pouco a pouco as professoras de Didática foram criando espaço para esta articulação e atualmente 4 das 10 responsáveis por esta disciplina, ao elaborar seus respectivos planos de curso passaram a incorporar a (re)aproximação com a escola 
como parte dos estudos e das atividades que desenvolvem com seus alunos, conforme explicitamos no tópico seguinte.

\section{De volta à escola sob a perspectiva de futuro professor}

Na UFF, a Faculdade de Educação (FEUFF) é a responsável pela oferta das disciplinas obrigatórias que compõem o Núcleo Comum das Licenciaturas. De acordo com a Resolução 616/2017 publicada pela Universidade Federal Fluminense (NITERÓI, 2018), este Núcleo compreende: Didática (60h), Organização da Educação no Brasil (60h), Psicologia da Educação (60h) e Libras I (30h). Portanto, cursar as 4 disciplinas é parte dos requisitos exigidos aos licenciandos para que concluam seus respectivos cursos de graduação.

Em linhas gerais, a vinculação às disciplinas ocorre no período de matrícula, no qual a Faculdade de Educação apresenta às coordenações dos cursos uma variedade de horários na tentativa de atender as demandas. Desse modo, os alunos, em acordo com a organização e as exigências curriculares de cada curso, procuram fazer suas matrículas no horário que melhor atende às suas especificidades e assim, as turmas são constituídas variando em quantidade e perfil de semestre a semestre.

Se nos estágios obrigatórios os estudantes das licenciaturas se integram às escolas com colegas de um mesmo curso, sob acompanhamento de professores da universidade e da escola de uma mesma área/disciplina, na Didática, a aproximação com a escola ocorre a partir da constituição de grupos de licenciandos de áreas distintas (Física, Cinema, História, Letras, Geografia, Biologia, Matemática, Filosofia e etc.), que se encontram em níveis/períodos variados. Na maior parte das vezes, esta é a primeira oportunidade de retorno à escola que esses jovens vivenciam desde que concluíram o ensino médio e para sua realização contarão com a participação e os olhares de colegas com experiências pessoais e trajetórias acadêmicas variadas.

Acreditamos que é justamente pelo fato de contarmos com esta diversidade que a atividade oferece horizontes que vão além das dimensões proporcionadas pelos estágios, possibilitando o cruzamento de pontos de vista mais amplos sobre a escola e as relações que ali se estabelecem e análises mais complexas que excedem o debate sobre o ensino e a aprendizagem de conteúdos específicos.

Neste caso, a ideia é oferecer aos estudantes uma (re)aproximação coletiva, com um ambiente bastante familiar que sob a condição de aluno da educação básica fez parte 
das suas vidas por mais de uma década (TARDIF, 2014). Agora, ao regressar sob a lente de futuro professor passam a ter acesso às nuances que até então não tinham sido percebidas (VASCONCELLOS; VILELA, 2017). Por essa e por outras razões, este momento de (re)aproximação é cautelosamente escolhido, cuidadosamente encaminhado e pode variar de semestre para semestre, de turma para turma, tendo em vista as demandas, os imprevistos, a variação do calendário escolar e o estudo da bibliografia que antecede esta entrada.

Para que este processo aconteça, fazemos esclarecimentos, conversamos com os estudantes sobre suas dúvidas, acertamos detalhes e definimos alguns pontos. No geral, tem prevalecido o seguinte acordo: 3 aulas de Didática (na UFF) serão disponibilizadas para a realização da atividade; a turma se organizará em grupos formados entre 3 e 5 alunos para que não gere tumulto nas escolas; cada grupo terá liberdade para eleger a escola e o ano/série de sua preferência; na escola, além de assistir as aulas de pelo menos um professor da disciplina de sua preferência, é importante dialogar com alunos e funcionários, incluindo diretores, coordenadores, professores, merendeiras, porteiros e outros; para que a atividade seja formalmente apresentada à escola, uma carta de apresentação será assinada pela professora de Didática e entregue, pelos licenciandos à Direção da escola; a professora de Didática entregará aos grupos um roteiro de observação com sugestões referentes aos aspectos que podem ser apreciados na escola e, ao final de cada dia, discutidos com os colegas.

Ao término do terceiro dia de aproximação com a escola, as atividades são retomadas na UFF e uma roda de conversa é realizada com a finalidade de compartilhar experiências, aprendizagens, dúvidas e anseios que costumam ser anunciados com entusiasmo e desejo de expressar as vivências e revelar percepções constituídas.

$\mathrm{Na}$ maior parte das vezes, os depoimentos são acompanhados por questionamentos que evidenciam interesse pelos relatos dos colegas e por comparações entre as experiências. Embora toda a atividade de (re)aproximação com a escola e a roda de conversa sejam realizadas de forma coletiva, um texto individual é produzido pelos licenciandos e entregue à professora de Didática, com o intuito de registrar as aprendizagens, expectativas, receios, hipóteses e outros elementos que este processo desencadeou. Aos alunos solicitamos que, se possível, o texto elaborado articulasse as reflexões suscitadas a partir dessa experiência, aos textos estudados nas aulas de Didática e/ou a outros lidos nas demais disciplinas. 
Foi a leitura dos registros produzidos em novembro de 2018 que suscitou o presente artigo, considerando que as respostas fornecidas oferecem informações relevantes acerca do debate sobre Didática e formação dos professores sob o enfoque da inovação pedagógica.

Vale acrescentar que as duas professoras de Didática que no segundo semestre de 2018 propuseram esta (re)aproximação, tinham a intenção de ocasionar desdobramentos que gerassem a constituição de perspectivas de ensino e aprendizagem que provocassem outras formas de se pensar e de se fazer escola. Perspectivas essas que contribuíssem com a formação profissional dos futuros professores, no sentido de extrapolar a simples observação das aulas e a mera transcrição de informações mecânicas sobre cada passo de um professor observado sob a luz de uma lanterna frágil, opaca e incapaz de iluminar os efeitos, a subjetividade e a complexidade inerentes à ação pedagógica.

Para nossa surpresa, as reflexões compartilhadas pelos 28 licenciandos, por meio do material escrito que produziram anunciam questões e preocupações com a escola que extrapolam o simples olhar para as aparências das relações pedagógicas que nela se estabelecem e convergem para um posicionamento que prima pela valorização de aspectos mais amplos, mais complexos e mais sutis. Para que possamos perceber tal convergência, apresentamos na sequência os excertos transcritos dos registros preparados por 3 dessas licenciandas, na tentativa de favorecer o acompanhamento do raciocínio expresso.

Denominadas, neste trabalho, por Laura, Tamires e Mariah, as estudantes nos oferecem informações potentes, no sentido da possibilidade de vislumbrarmos caminhos que provoquem pequenas fissuras nas relações entre ensinar e aprender, desencadeadas a partir das reflexões que a aula de campo lhes provocou. As 3, elegeram escolas públicas localizadas no município de Niterói/RJ, sendo uma delas federal e as outras duas estaduais.

Vejamos o que nos dizem as futuras professoras:

Além de estar ali para aprender observando novas experiências e ensinamentos, estava novamente naquela escola com um novo objetivo: ensinar. Algo que achei que nunca seria capaz de fazer até perceber que meu lugar é a sala de aula. Mostrando que a sala de aula não deve ser apenas um local de exibição de conteúdos, porque ela deve estar muito além disso. Deve ser o local onde professores e alunos possam trocar ideias, dialogar e refletir. Ela deve ser o espaço 
de resistência do professor e do futuro (como eu). Antes, eu via a escola como um castigo, pois, antes era vista como obrigação e imaginava que nunca mais voltaria. Hoje em dia, com mais maturidade, mudei totalmente minha perspectiva e vejo a escola como espaço de convivência e de construção social das crianças, sendo necessária sua presença no processo de individuação dessas crianças na sociedade. Nesse espaço de construção quero atuar e ajudar a formar indivíduos que critiquem e reflitam para que possamos construir uma sociedade melhor, mais justa (LAURA).

Antes de falar das perspectivas gostaria de falar do agora. É muito estranho perceber o quanto minha visão sobre a escola já mudou. Nesse trabalho de campo isso ficou muito visível. Ao chegar à escola ficamos observando o ambiente, como o professor trabalha, como os alunos se sentem e se a metodologia é efetiva. As preocupações mais voltadas para o social e para como os alunos se sentem me escapavam um pouco. Achava que o importante era o professor estar na escola e ensinar o conteúdo da melhor forma (que geralmente era abordando bem o que caía no ENEM). A preocupação com o que fazer quando chegasse a minha vez de estar diante de uma turma foi grande. A realidade da escola, principalmente a pública, é muito delicada (além da precarização, da concorrência com o tráfico, da gravidez na adolescência, evasão, entre tantas outras coisas fazem desse ambiente um lugar necessitado de mudanças). Até o momento penso nisso: o que poderei fazer? Espero fazer com que os alunos não enxerguem a Física como um demônio, mas além de ensinar o conteúdo gostaria de conseguir me conectar a eles, oferecer novas perspectivas, auxiliá-los. O professor não é um mágico, existem coisas que estão além do nosso alcance, mas temos acesso a muitos e isso é lindo demais! Espero que eu consiga compartilhar conhecimentos, experiências e aprender muito, tanto hoje com amigos e professores, como futuramente com meus alunos (TAMIRES).

Apresentada então à escola e às suas estruturas filosóficas e pedagógicas, posso relatar agora o que significou para mim voltar a esta escola. A primeira sensação é de retorno ao passado e voltar ao passado nem sempre é algo repleto de boas lembranças ou nostalgias que nos fazem sentir bem ou abraçados pela nossa própria história. Há muitos sentimentos confusos e/ou até dramáticos ou traumáticos que aparecem nesses momentos, sem que sejam solicitados. A minha relação com a escola em que estudei na maior parte do tempo, não foi de fato uma experiência muito satisfatória na maior parte do tempo. Acredito que por ser uma escola muito rígida, focada nos resultados, exames e provas. Tínhamos o lado criativo pouco estimulado e muitas vezes, éramos chamados de 'medíocres' por simplesmente mantermos as notas na média (7). Portanto, o retorno para mim é a possibilidade de ressignificar a ideia de escola. Sem dúvida o curso de licenciatura me proporcionou essa visão da educação mais libertária e inclusiva, longe de metodologias de ensino antigas e excludentes. Hoje, reconheço o laboratório de potencialidades desse espaço que pode criar uma nova perspectiva de sociedade e de paradigmas importantes. Além disso, apesar de muitas contradições é bom presenciar uma escola que se coloque de maneira diferente da maioria de formatos extremamente meritocráticos e duvidosos. É no mínimo um suspiro no 
meio do caos. Portanto, para mim, voltar a escola é voltar ao passado e se abrir para o futuro. Se essa é a profissão que escolhi, que meus colegas escolheram, as perspectivas se pretendem infinitas, pois, eu realmente acredito que a cada esquina há uma saída (MARIAH).

Frente à riqueza das informações desveladas nos excertos, o que ainda podemos dizer sem que sejamos redundantes? Sem que caiamos na tentação de dizer o óbvio? Não temos como garantir que não cometeremos este deslize, mas asseguramos que nos esforçaremos para seguirmos um pouco mais adiante.

Perante este desafio iniciamos nossas análises retomando a discussão sobre inovação pedagógica, o que exige reiterarmos que, para além da inserção de aparatos tecnológicos variados, inovar pedagogicamente requer alteração qualitativa das práticas escolares. Essas alterações demandam sempre “[...] um posicionamento crítico, explícito ou implícito, face às práticas pedagógicas tradicionais [...]. Se quisermos colocar a questão em termos de ruptura [...] a inovação pedagógica pressupõe um salto, uma descontinuidade" (FINO, 2008, p. 01).

Ao falarmos sobre descontinuidade, estamos nos referindo "[...] ao velho e omnipresente paradigma fabril [...] que acontece localmente no espaço físico ou virtual onde se movem aprendizes e professores funcionando estes, deliberadamente como agentes de mudança". Isso exige "[...] criação de contextos de aprendizagem, incomuns relativamente aos que são habituais nas escolas, como alternativa à insistência nos contextos de ensino" (FINO, 2008, p. 01).

E por que razão retomamos as discussões sobre inovação pedagógica, justamente neste momento? Em que medida, este assunto dialoga com as informações oferecidas pelas 3 licenciandas?

Com a intenção de aprofundar estas questões, extraímos dos registros de Laura, Tamires e Mariah os principais elementos que os compõem, nos quais a escola que aspiram ajudar a ressignificar é concebida como ambiente de:

- resistência e atuação profissional;

- $\quad$ superação de práticas que valorizam a mera transmissão de conteúdos;

- troca de ideias, reflexão e diálogo entre professores e alunos;

- convivência, formação individual e social;

- construção de uma sociedade mais justa em detrimento da valorização da meritocracia e de processos excludentes. 
Se tomarmos como referência os esclarecimentos de Fino (2008) e Cunha (2016) e os cotejarmos aos dados decorrentes dos depoimentos das 3 licenciandas verificaremos a prevalência de aspectos comuns que apontam para o anseio da formação de uma sociedade verdadeiramente humana. Entre outras coisas, isso requer a consolidação de princípios que envolvam dimensões de afeto, escuta, diálogo, compromisso e solidariedade, além do reconhecimento político e social de que a escola é o espaço propício a sua concretização e, portanto, principal locus dessa formação.

Em síntese, o que os dados teóricos e empíricos nos oferecem não são elucubrações sobre a relevância ou não da escola em nossa sociedade. Inversamente, nos provocam e muito a redefinir as políticas, os conteúdos, as escolhas, os encaminhamentos, o tipo de comunicação e, principalmente, a qualidade das relações que nela e com ela se instituem.

\section{Inovação pedagógica na perspectiva de professores das escolas básicas}

A aproximação com o espaço da escola básica tem sido uma demanda constante dos licenciandos. Os estudantes, durante as aulas de Didática, são enfáticos ao afirmar que não se sentem preparados para lecionar, que existe uma distância entre a escola real e o que aprendem ao longo do curso de formação de professores. Suas demandas por uma formação mais próxima da realidade das escolas têm eco nas pesquisas que se dedicam a estudar a formação docente, como afirmam Cruz e Campelo (2016, p. 96)

\footnotetext{
As pesquisas que se dedicam a essa temática têm suscitado muitas preocupações sobre os atuais moldes de formação docente. Ao tratar da formação inicial dos professores para a educação básica, muitos estudos têm constatado uma distância entre o processo de formação inicial dos professores e a realidade encontrada nas escolas, que diz respeito à lacuna entre a teoria estudada nas universidades e a prática desenvolvida no ambiente profissional, entre a formação e o trabalho (COCHRAN; LYTLE, 1999; ROLDÃO, 2007; ZEICHNER, 2010).
}

A escuta das demandas dos licenciandos, provocou as professoras do Núcleo de Didática a buscar estratégias que contribuíssem para a reflexão/ação sobre o espaço escolar, como local privilegiado para a problematização de questões que envolvem a profissão. Assim, as aulas de campo realizadas nas escolas têm servido de insumo para discussões sobre o ser professor e sobre as angústias que giram no seu entorno. Ainda que permeada por dúvidas temos percebido em nossas aulas, que a maioria dos 
estudantes deseja ser professor e vê a (re)aproximação com a escola como parte importante da sua formação.

Para ampliar esse contato com a escola básica, no primeiro semestre de 2018, além da (re)aproximação proposta, solicitamos aos licenciandos de uma das três turmas envolvidas que entrevistassem os professores que acompanharam, desde que em seus pontos de vista apresentassem práticas pedagógicas que considerassem inovadoras.

Ainda sem discussão teórica prévia sobre este conceito, tomamos tal iniciativa por termos a intenção de provocar reflexões iniciais, baseadas nas concepções dos licenciandos e dos professores da educação básica visando sua revisão e a composição de conhecimentos a propósito do assunto. Desse modo, foi possível fomentar discussões e avançar nos processos subsequentes da disciplina, em especial, nos estudos e oficinas realizadas com eles sobre planejamento didático. Assim sendo, ao retornar da escola, tomamos por referência o entrecruzamento entre o ponto de vista dos professores, as concepções dos licenciandos e a literatura que discute inovação pedagógica (FINO, 2008; CUNHA, 2016).

Foi assim, que organizados em grupos que abrangiam de 4 a 5 estudantes em média, os licenciandos partiram para o campo desejosos por interagir e ouvir o que os professores escolhidos por eles tinham a dizer.

Destaca-se que, embora o interesse fosse entrevistar professores que os estudantes considerassem que desenvolviam práticas inovadoras, as perguntas versaram especificamente sobre as práticas. Não foi perguntado o que é inovação, mas como os professores e professoras entrevistados trabalham, como são suas aulas, suas escolhas pedagógicas. Essa escolha foi fundamental para que as respostas não ficassem restritas a tentativa de conceituar inovação, mas sim, ouvir o que tinham a dizer sobre suas práticas.

O principal tema abordado pelos professores entrevistados foi a importância da escuta do aluno como caminho para o aprendizado da docência. Ao falar sobre esta questão, a professora Maria, por exemplo, que atua na Educação Infantil, nos fornece informações que ilustram este entendimento: "É uma prática sempre reflexiva, a gente se torna e se faz professora a cada dia e a cada momento, estudando e ouvindo o outro".

Sobre esse aprendizado, Andreia, outra professora da Educação Infantil, faz uma afirmação que complementa a compreensão anterior. Nas suas palavras, 
O que a criança diz importa, a curiosidade dela importa, esse é o contributo da infância. É o olhar diferenciado de alguém que está vendo o mundo pela primeira vez, que desconhece isso que a gente já tá muito acostumado a ver. Então, esse é um princípio fortemente defendido aqui na educação infantil, a questão da escuta. É o que a criança diz e os interesses da criança que vão fazer a linha de direção do nosso trabalho (PROFESSORA ANDREIA).

Como destaca Cunha (2016, p. 97) os professores e professoras entrevistados, buscam por meio da escuta atenta as demandas dos estudantes, “[...] a autoria e o protagonismo dos alunos numa perspectiva emancipatória”. O professor Richard, que leciona Filosofia no Ensino Médio, destaca a importância de instigar os alunos a se ouvirem mutuamente:

Como professor eu estimulo que meus alunos ouçam os outros. Isso é muito difícil, em última instância, eu não posso forçar ninguém a ouvir o outro. Eu só posso tentar criar estímulos para isso. Um desses estímulos precisa ser: eu mesmo como professor preciso estimular isso cotidianamente e dar esse exemplo de que o aluno pode falar e ser ouvido. Se ele se sente ouvido, ele vai ficar mais predisposto a ouvir também (PROFESSOR RICHARD).

Não temos como assegurar que o exemplo do professor seja suficiente para que uma conduta sensível a escuta do outro reverbere de modo efetivo entre os alunos. De todo modo, compactuamos com o entendimento dos professores entrevistados, sobre a relevância deste assunto e advertimos que consideramos urgente a adoção de práticas que provoquem rupturas com o predomínio do falar para o outro, em decorrência do desenvolvimento de processos que vislumbrem escutar a escuta do outro.

A esse respeito, Freire (1996) acrescenta:

Se, na verdade, o sonho que nos anima é democrático e solidário, não é falando aos outros, de cima para baixo, sobretudo, como se fôssemos os portadores da verdade a ser transmitida aos demais, que aprendemos a escutar, mas é escutando que aprendemos a ferir com eles. Somente quem escuta paciente e criticamente o outro, fala com ele (1996, p. 43).

Para Paulo Freire, a escuta do aluno é um aprendizado necessário à docência e, embora não tenhamos uma trajetória escolar predominantemente pautada por este enfoque “[...] não é difícil perceber como há umas tantas qualidades que a escuta legítima demanda do seu sujeito. Qualidades que vão sendo constituídas na prática democrática de escutar" (1996, p. 45).

Ouvir nossos alunos e alunas e criar espaço para que se ouçam é, antes de mais 
nada, parte importante de um exercício que tende a provocar aprendizagens sobre a democracia, por meio de processos que em si, podem ser democráticos. Entretanto, no dia a dia, temos percebido o predomínio da imposição de uma maneira de pensar sobre outra na qual, independentemente do ponto de vista que se defende, não existe o interesse de ouvir quem pensa ou discursa de outra maneira que não a minha (FREIRE, 1996). O problema, é que a manutenção dessa postura alimenta a opressão, silencia vozes, fortalece desigualdades e injustiças sociais e põe em risco a construção de um projeto de sociedade - e de escola - que se pretende democrática. Desse modo, um tema tão caro e relevante a qualquer sociedade, em nosso país, tem sido suprimido pela retórica conservadora que

[...] tem buscado espalhar o medo e a insegurança através de discursos moralizantes, como forma de abrir caminho para o conservadorismo político, devassar as possibilidades de avanço social e democrático, construídas nos últimos quinze anos, no Brasil (MACIEL; JAEHN; VASCONCELLOS 2018, p. 1505).

Essa tentativa de ação, via ampliação do discurso conservador, que visa anular a discussão crítica do espaço da sala de aula, se choca com o desejo dos estudantes de compreender a complexidade desse momento político e com o papel da própria escola, como afirma o professor de História do Ensino Médio, Augusto:

O que tem acontecido muito atualmente, por exemplo com esse clima de instabilidade política que a gente vive é, muitas vezes, os alunos chegarem com questões sobre como funciona a política, como é a democracia na prática, o que é fascismo. Questões desse tipo que eu acho que eu, professor, não tenho como ignorar (PROFESSOR AUGUSTO).

Para desenvolver atitudes comprometidas com o respeito pelo outro, reconhecendo e valorizando suas singularidades, a variação entre os tempos e os saberes de cada um, a professora da Educação Infantil, Adriane, ressalta que o planejamento escolar é um desafio da contemporaneidade, tendo em vista que a organização prévia do professor é essencial, todavia, para que faça sentido é necessário considerar que "No dia a dia, as crianças vão conduzindo o nosso trabalho".

Mesmo sendo uma prática comum a professores e professoras, o planejamento e a organização do trabalho docente ainda têm sido pensados, prioritariamente, a partir de um ideal de criança distante, da criança real (FAGUNDES, 2011). Para os professores e professoras que fizeram parte de nossa pesquisa, é justamente a proximidade com os 
jovens e as crianças presentes nas instituições escolares nas quais os futuros professores trabalharão que será possível estabelecer laços de afeto e diálogo que nos incitam a perceber as diferentes nuances que emergem em sala de aula.

Como afirma Fino (2008, p. 5) “[...] a inovação pedagógica só se pode colocar em termos de mudança e de transformação", não é uma tecnologia que se importa ou algo que possa ser quantificado em termos de eficácia pedagógica. O que os professores e professoras entrevistados evidenciam em suas falas é que, para além de uma questão de método ou de planejamento didático inovação pedagógica passa pela autonomia docente, dialogicidade, criatividade e escuta do outro.

\section{Considerações Finais}

A aproximação com o espaço da escola básica tem sido uma demanda constante dos licenciandos, que afirmam que o curso de formação de professores não tem dado conta de prepará-los para lecionar, em parte pela distância entre a escola real e o que aprendem sobre a escola na universidade. Discussões que coadunam com esta perspectiva têm nos instigado e nos provocaram a rever e alterar nossas práticas como formadoras de professores, responsáveis pela disciplina de Didática, na Faculdade de Educação da UFF, conforme explicitamos no corpo do texto.

Os processos e os resultados desse trabalho nos instigaram a revisitar o material produzido pelos licenciandos, sob o enfoque da literatura que discute inovação pedagógica. Este movimento ocorreu em razão do fato de que, tanto em nosso grupo de Pesquisa Formar ${ }^{5}$, como no grupo de professores que constitui o Observatório Internacional de Inclusão, Interculturalidade e Inovação Pedagógica, este conceito tem sido amplamente estudado (FINO, 2008; CUNHA, 2016, entre outros).

Foi assim que, inspiradas pelos esclarecimentos desses estudiosos que nos debruçamos sobre o material produzido, com o objetivo de identificar elementos que apontem perspectivas pedagógicas inovadoras, sob a ótica de licenciandos e professores da educação básica.

Por meio de registros individuais e das entrevistas com docentes da educação básica, suscitadas pela aula de campo denominada (re)aproximação com a escola, que identificamos elementos das práticas pedagógicas investigadas que revelam a tentativa,

\footnotetext{
${ }^{5}$ Grupo de Pesquisa em Didática, Formação de Professores e Práticas Pedagógicas/CNPq
} 
por parte dos professores e professoras, de provocar descontinuidades de uma prática tradicional de ensino e superar a mera transmissão de conhecimentos no espaço da sala de aula. Os materiais produzidos expressam também, mesmo que em pequena escala, a assunção de escolas que têm buscado priorizar aspectos como escuta do outro, afetividade, autonomia docente, dialogicidade, compromisso e criatividade.

Para os estudantes o contato com professores e professoras da escola básica foi uma oportunidade ímpar de troca de ideias, reflexão e diálogo realizada no interior do futuro espaço profissional.

Destaca-se, neste texto, que a busca por uma prática pedagógica inovadora passa, essencialmente, pelo reconhecimento político e social de que a escola é o principal locus de formação de professores e pela urgência de refletirmos coletivamente - universidade e escola - sobre outras formas de se pensar e se fazer escola, mas também sobre outras formas de se pensar e se fazer formação docente.

\section{REFERÊNCIAS}

BRASIL. Ministério da Educação. Censo do Ensino Superior 2017. Disponível em: http://portal.mec.gov.br/docman/setembro-2018-pdf/97041-apresentac-a-o-censosuperior-u-ltimo/file. Acesso em: 22 mar. 2019.

CANDAU, V. Didática crítica intercultural: aproximações. Petrópolis, RJ: Vozes, 2012.

CRUZ, G. B. da; CAMPELO, T. Parceria universidade-escola básica e a aprendizagem da docência: contribuições da relação entre os professores supervisores do PIBID e os licenciandos bolsistas. Formação Docente, Belo Horizonte, v. 09, n. 15, ago./dez., 2016. Disponível em: http://formacaodocente.autenticaeditora.com.br . Acesso em: 14 maio 2019.

CRUZ, G.; OlIVEIRA, A. T. de C. C. de; NASCIMENTO, M. das G. C. de A. Ensino de Didática: entre ressignificações e possibilidades. Curitiba: CRV, 2017.

CUNHA, M. I. Inovações na educação superior: impactos na prática pedagógica e nos saberes da docência. Em Aberto, Brasília, v. 29, n. 97, 2016, p. 97-101.

DOMINICK, R.; VASCONCELLOS, M.; ALVES et al. Ensino de Didática: entre ressignificações e possibilidades na FEUFF. In: CRUZ, G.; OLIVEIRA, A. T. de C. C. de; NASCIMENTO, M. das G. C. de A. Ensino de Didática: entre ressignificações e possibilidades. Curitiba: CRV, 2017.

FAGUNDES, T. B. A pesquisa docente: sobre o conceito de professor pesquisador na formação inicial de agentes de letramento. 2011. 157f. Dissertação (Mestrado em Educação) - Faculdade de Educação, Universidade do Estado do Rio de Janeiro, Rio de 
Janeiro, 2011. Disponível em: http://proped.pro.br/teses/teses_pdf/2009_1-571-ME.pdf Acesso em: 16 maio 2019.

FINO, C. N. Inovação Pedagógica: Significado e Campo de (Investigação). In Alice Mendonça \& António V. Bento (Orgs.). Educação em Tempo de Mudança (pp. 277 287). Funchal: Grafimadeira, 2008. Disponível em:

http://www3.uma.pt/carlosfino/publicacoes/Investigacao_e_inovacao.pdf .

FREIRE, P. Pedagogia da Autonomia: saberes necessários à prática educativa. São Paulo: Paz e Terra, 1996.

GATTI, B. Educação, escola e formação de professores: políticas e impasses. Educar em Revista, Curitiba, Brasil, n. 50, p. 51-67, out./dez. 2013. Editora UFPR.

GAUTHIER, C. et al. Por uma teoria da pedagogia: pesquisas contemporâneas sobre o saber docente. Ijuí: Ed. UNIJUÍ, 1998. 480p.

HERNÁNDEZ, F., VENTURA, M. A organização do currículo por projetos de trabalho. Porto Alegre: Artmed, 1998.

LÜDKE, M.; ANDRÉ, M. E. D. A. Pesquisa em educação: abordagens qualitativas. 8. ed. São Paulo: EPU, 2004.

MINAYO, M. C. de S. (Org.). Pesquisa Social: teoria, método e criatividade.

Petrópolis, RJ: Vozes, 2003.

MACIEL, S.; JAEHN, L.; VASCONCELLOS, M. Precisamos falar de gênero: por uma educação democrática. Revista Ibero-Americana de Estudos em Educação, v. 13, p. 1503-1517, 2018. Disponível em:

https://periodicos.fclar.unesp.br/iberoamericana/article/view/11657/7602 . Acesso em: 14 maio 2019.

MIZUKAMI, M. da G. N. Analisando a função social da escola: a inserção do pedagogo na vida escolar durante o primeiro ano de curso. In: SILVA, A. M. M. et. al. (Orgs.). Políticas educacionais, tecnologias e formação do educador: repercussões sobre a didática e as práticas de ensino. Recife: ENDIPE, 2006. p. 65-81.

NITERÓI. Universidade Federal Fluminense. Resolução nº 616, de 2018. Estabelece a Base Comum para os Cursos de Licenciatura da UFF. Disponível em:

http://www.uff.br/sites/default/files/sites/default/files/imagens-das-noticias/20._0152018_-_resoluaeo_616-17_base_comum_licenciaturas.pdf. Acesso em: 17 maio 2019.

NOVOA, A. Os professores: um "novo" objecto da investigação educacional?. In: NOVOA, A. (Org.). Vidas de professores. 2. ed. Porto: Porto Editora, 1999. p. 13-30.

NÓVOA, A. Os professores: um novo objeto de investigação educacional? In:

NÓVOA, A. (Org.). Vidas de professores. 2. ed. Porto: Porto Editora, 2015. p. 13-30.

PERRENOUD, P. O trabalho sobre o habitus na formação de professores: análise das práticas e tomada de consciência. In: PERRENOUD, P. et.al. (Orgs.). Formando 
professores profissionais: Quais estratégias? Quais competências? Porto Alegre: Artmed Editora, 2001. p. 161-184.

SHULMAN, L. Knowledge and teaching: foundations of the new reform. Harvard Educational Review, n. 1, p. 1-22, February 1987.

SHULMAN, L., GROSSMAN, P. L., WILSON, S. M. Teachers of substance: subject matter knowledge for teaching. In: REYNOLDS, M. C. (Org.). Knowledge base for the beginning teacher. New York: Pergamon Press, 1989. p. 23- 36.

TARDIF, M. Saberes docentes e formação profissional. 5. ed. Petrópolis, RJ: Vozes, 2014. 325p.

TERRIEN, J. O saber social da prática docente. Educação \& Sociedade, Campinas, n. 46, p. 408-418, dez. 1993.

VASCONCELLOS, M.; SANTIAGO, M. C. D. Grupo de Pesquisa Formar: Inovação ou reinvenção de saberes? Revista Educação e Fronteiras, Dourados/MS, v. 8, n. 22, p. 35-46, jan./abr. 2018.

VASCONCELLOS, M.; VILELA, M. Limites e possibilidades da formação inicial para o desenvolvimento de práticas autônomas. Educar em Revista, Curitiba, Brasil, n. 63, p. 157-172, jan./mar. 2017.

VASCONCELLOS, M.; OLIVEIRA, L. F. de; MENEZES, G. L. P. de. Formação superior e opção pelo magistério: quais são as razões apresentadas por alunos das licenciaturas para sua escolha profissional? In: SANTIAGO, M. C. e AKKARI A. (Orgs) Formação de professores: perspectivas interculturais. Rio de Janeiro: Autografia, 2016. p. 35-56.

\section{Como referenciar este artigo}

VASCONCELLOS, Mônica; MACIEL, Sandra. Por uma outra escola: provocações à didática e ao conceito de inovação pedagógica. Revista on line de Política e Gestão Educacional, Araraquara, v. 23, n. esp. 1, p. 743-765, out. 2019. E-ISSN:1519-9029. DOI: https://doi.org/10.22633/rpge.v23iesp.1.13006

Submetido em: 10/05/2019

Revisões requeridas: 14/06/2019

Aprovado em: 10/08/2019

Publicado em: 01/10/2019 